\title{
Business Model Design for Smart Energy Integrated Service Platform From the Perspective of Value Flow
}

\author{
Suxiu Li, Xingtong Chen and Lin Liu*
}

\author{
Energy Internet Research Centre, State Grid Energy Research Institute \\ *Corresponding author. Email: lisuxiu@163.com
}

\begin{abstract}
The smart energy integrated service platform essentially builds a platform-based business model based on the concept of "energy+ internet", wherein, traffic is a key element and resource. Based on the value flow theory, this paper constructed a research framework for the value flow mechanism of the platform business model, and analyzed the logic of the platform business model under business flow, data flow, and capital flow. "Traffic attraction $\rightarrow$ traffic distribution $\rightarrow$ traffic monetization", all promote the development of the platform business model, thereby forming the value flow path of the smart energy integrated service platform business model, and promote the closed loop iteration of business processes. Thus the paper clarified the value flow path and business process logic of the designed platform business model.
\end{abstract}

Keywords: Smart energy integrated service platform, Energy+ internet, Value flow theory, Platform business model.

\section{INTRODUCTION}

The development of smart energy integrated services has become a growth point for enhancing energy efficiency and expanding new businesses, and an important development direction for promoting competition and cooperation. The smart energy integrated service platform integrates multiple functions such as energy monitoring, energy analysis, energy management, energy services, energy transactions, and energy ecology. It is involved in the entire process of energy industry services, provides green, safe, economical, efficient, and value-added integrated energy information intelligent services to governments, energy consumers, energy operators, energy products, service providers, and other users, and builds a win-win and shared energy ecosystem.

The smart energy integrated service platform essentially builds a platform-based business model based on the concept of "energy+ internet", wherein, traffic is a key element and resource. Similar to the traffic in Internet of Thinking, the traffic of the smart energy integrated service platform is formed by customers, which is the means and key to realize business development and value monetization. But unlike the traffic in Internet of Thinking, the traffic of the smart energy integrated service platform is endowed with value creation connotations and tasks, and also accompanies business and data information.

The value mechanism of business model innovation and platform strategy is analyzed based on the value perspective, and a research framework for the value flow mechanism of the platform business model is built in this paper. Then, a smart energy integrated service platform business model design is formulated keeping in mind the business architecture characteristics and innovation requirements of the platform, and the logic characteristics of the platform business model are clarified from the perspective of business flow, data flow, and capital flow, to clarify the value flow path and business process logic of the designed platform business model.

\section{THEORETICAL BASIS}

\subsection{Literature Review}

\subsubsection{Value Creation Perspective of Business Model Innovation}

Innovation scholar Schumpeter, proposed that innovation is the re-combination of various production factors [1]. To maintain a competitive edge in the long 
run, enterprises must rely on continuous innovation, including technological innovation, organizational innovation, cultural innovation, and business model innovation. Among them, technological innovation is the source of human wealth and a huge driving force for economic development. The competitiveness of an enterprise largely depends on its technological innovation capabilities [2]; however, to achieve transformative growth, enterprises often depend not only on products or technological innovation, but also on business model innovation [3]. The success of companies such as Walmart and Amazon is a result of business model innovation.

As for the theoretical research on business models, the most common research perspective is the concept and connotation of value creation. Based on the value theory, a business model is a business logic that describes how an enterprise creates, delivers, and obtains value based on its own characteristics.

Therefore, a business model from the perspective of value creation is analyzed and designed based on the main logic of creation and transmission of value.

\subsubsection{Value Network Perspective of the Platform Strategy and Platform Model}

At present, more and more companies are adopting platform strategies to innovate business models and promote innovation performance. At least $60 \%$ of the world's top 100 companies by market capitalization are earning more than half of their revenue through the platform market [4]. In today's mobile internet era, not only are internet companies adopting platform-based business models, but also traditional manufacturing industries, energy companies, service-oriented companies, and administrative agencies, have started to consider the impact of platforms and business ecology on the transformation and upgrade of their respective enterprises. The reason why platforms can create value is that they are of great economic importance and are value-creating assets with paradigm characteristics [5].

The research on platform strategy primarily has three supporting theories-external empowerment theory, value network theory, and VCUA environmental theory. The value network in the value network theory refers to the value creation, exchange, and transfer network formed between different market entities, different industries, different times, and different locations [6]. Value creation in the network has shifted its focus from improving the efficiency of the supply chain to network collaboration. Different actors in the value network need to innovate more actively and interact and cooperate with other relevant entities to generate value co-creation.

Therefore, the platform strategy in terms of the value network is to clarify the role of the platform in the process of value flow and the relationship between the entities in the platform.

\subsection{Research Framework of Value Flow Mechanism of Platform Business Model}

In terms of value creation, the business model clarifies and explains the process of value creation, transmission, and acquisition. From the value network perspective, the platform strategy explains the entities and their relationships in the value transmission, sharing, and exchange process, and clarifies the direction of value flow. Therefore, the key to the business model and platform strategy points to the core concept of "value flow".

Hence, the platform business model can be explained by value flow theory. Value Flow Theory is also referred to as "World Economic Flow Study" or "Zhu Ming Economics", which was proposed by Zhu Ming in 2003, a famous economic observer and economist known as the "Father of World Economic Philosophy" and "The Father of Phenomenological Economics". The theory is still being continuously enriched, improved, and researched. It points out that value flow refers to all activities that transform raw materials into finished products and bestow value on them, including the entire process of the company purchasing raw materials from suppliers, processing and transforming them into finished products, and then delivering the finished products to the customers. The information flow formed by information communication between enterprises, suppliers, and customers is also part of the value flow. The value flow in a broad sense covers various types of "flow" that can create and deliver value, such as business flow, capital flow, and information flow (data flow) [7].

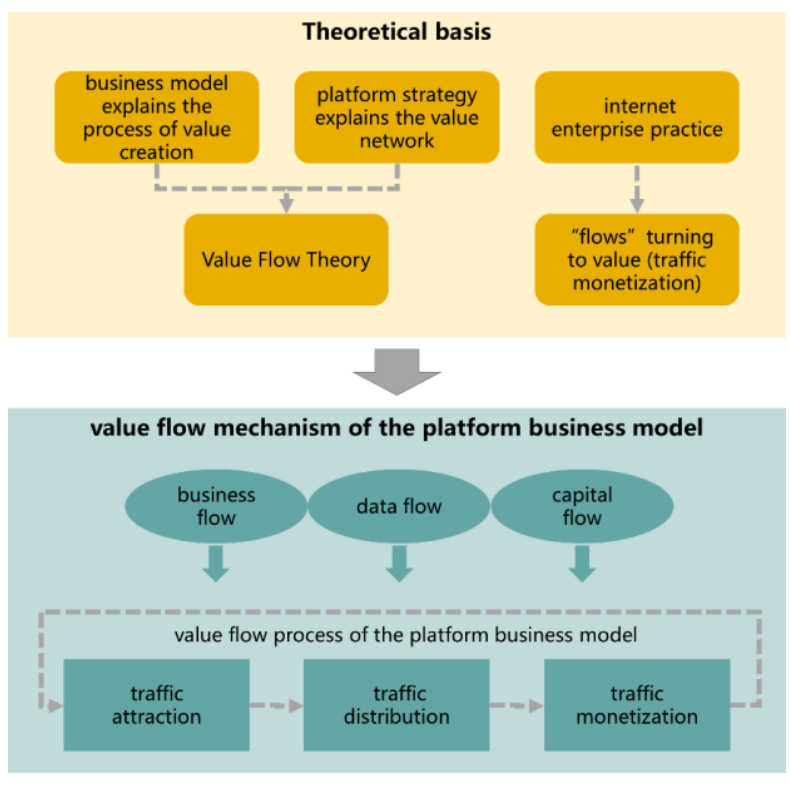

Figure 1 Research framework of value flow mechanism of the platform business model. 
From the perspective of internet enterprise practice, value flow is endowed with several links such as traffic attraction, retention, and monetization, which constitute the value flow and creation logic of "traffic attraction $\rightarrow$ traffic distribution $\rightarrow$ traffic monetization", which is in line with the flow logic based on value flow theory.

Therefore, by combining theory and practice, a research framework for the value flow mechanism of the platform business model (Figure 1) is constructed in this paper.

\section{CHARACTERISTICS AND INNOVATION NEEDS OF SMART ENERGY INTEGRATED SERVICE PLATFORM FROM THE PERSPECTIVE OF VALUE FLOW}

\subsection{Business Structure Analysis of Smart Energy Integrated Service Platform}

Based on the value flow theory and the characteristics of the smart energy integrated service platform, its related businesses can be divided into four major segments: business traffic attraction, platform core, security support, and expansion.

The business traffic attraction segment is primarily used to bring in customer traffic and data traffic to the platform, to achieve rapid convergence of various resources. Bringing in customer traffic increases platform user activity, expands platform visibility, increases customer stickiness, and provides customer resources for the construction and operation of other segments of the platform. By bringing in data traffic, the platform can obtain more abundant professional and accurate energy data, achieving comprehensive status perception on the customer side, and acquire valuable data resources for the platform to carry out energy analysis, energy efficiency services, industry research, and so on. Typical products and services in this segment include information release and data subsidies.

As the core of the integrated energy service platform construction, the platform core segment serves individual and corporate users, empowers the parties involved in the integrated energy service, and maximizes the platform-based functions of the integrated energy service platform. It deepens platform attributes, reduces information asymmetry, reduces intermediate links, and efficiently promotes the connection between service providers and users. At the same time, it creates a win-win ecosystem for supplyside companies. A multi-party collaborative platform model can enrich platform service capabilities, promote platform self-evolution, rapid innovation, and flexibly respond to the needs of different users. It also provides platform-based services for different types of energy users. Typical product services include application markets, technology empowerment, transaction matching, group purchases, and centralized procurement.

The security support segment primarily uses the brand background advantages of energy internet companies to empower platform users. On the one hand, it can provide assurance and support for the business development of energy service providers and upstream and downstream enterprises in the industry chain and reduce the risk in entering the market. On the other hand, the platform can quickly win the market and eventually build an ecosystem of mutual assistance and win-win results by providing support services for enduser-oriented social integrated energy service enterprises. The main products and services of this segment include credit endorsement, energy insurance, and qualification certification.

The expansion segment is based on platform business types with added value extended from the main business segments of the platform. With the expansion of platform scale and the deepening of various services, new user requirements and platform extension services gradually emerge, including product services such as basic public energy cloud platform services and big data services.

The four major segments together constitute the overall business structure of the smart energy integrated service platform. From the perspective of value flow, the segments are in line with each other and promote the value creation logic of the smart energy integrated service platform.

\subsection{Innovative Needs of Smart Energy Integrated Service Platforms from the Perspective of Value Flow}

The support provided by the internet in industry transformation, provides an important opportunity for the development of integrated energy services. The current integrated energy service platforms in the market have their own shortcomings, and existing platforms of various companies cannot fully meet market needs. The current business model innovation of smart energy integrated service platform faces four requirements:

1. Attract platform traffic, increase user participation, form user stickiness, and tap platform potential. By increasing customer traffic, the platform can gradually build customer stickiness and cooperate using relevant technical means to further accurately recognize customers and tap more user needs.

2. Deepen the attributes of the platform, take the platform as the core, match the interests of supply and demand parties, and generate platform value. In response to the needs of different suppliers and 
consumers, establish a trading and sharing platform for products, services, and technologies.

3. Focus on platform governance and use technology and management methods to promote the linkage between upstream and downstream of industry chain to form a good ecological and brand advantage. In response to the requirements of integrated energy service qualification certification, financial insurance, credit assurance, etc., the brand image of relevant large enterprises is endorsed to give full play to the industry's leading role.

4. Expand the value chain, dynamically manage the business functions of the platform, and innovate business models based on demand. With the expansion of the platform scale and the improvement of the industry development level, it is possible to innovate business models and dig deeper into the platform functions in response to the dynamic development of market demand and industry technology level.

With the rapid development of the internet industry, and leveraging internet's inherent advantages of convenience, flatness, scale, agglomeration, and openness, traditional industries are facing constant cross-industry disruption. This provides an important opportunity and is an inevitable trend for the development of integrated energy services. However, both the integrated energy service platform developed by an internet company and the internet platform built by an energy company have shortcomings, such as imperfect business planning, insufficient integration of data services, inadequate network resource deployment, insufficient terminal application levels, and low user willingness to participate. Therefore, the platform cannot achieve good use effect and user experience, and it cannot meet commercial expectations.

Therefore, designing a smart energy integrated service platform business model based on the perspective of value flow and Internet of Thinking, can help in the effective connection and in-depth comprehension of market needs, and bring to the fore innovative platform development models.

\section{BUSINESS MODEL DESIGN OF SMART ENERGY INTEGRATED SERVICE PLATFORM}

\subsection{Business Model Logic based on Value Flow}

Business flow, data flow, and capital flow together constitute the carrier of value creation and flow from the perspective of value flow, and provide clear value creation logic for business model innovation. They all follow the current traffic logic of "traffic attraction $\rightarrow$ traffic distribution $\rightarrow$ traffic monetization".
In the business architecture of the smart energy integrated service platform, business flow, data flow, and capital flow are the main logical nodes, which together comprise an interconnected whole that supports the operation of the platform. Fully clarifying the business logic relationship can ensure more comprehensive, scientific, and ecological platform construction and operation.

\subsubsection{Platform Business Model Logic under Business Flow}

From the perspective of business flow, the business logic of the smart energy integrated service platform business model is - traffic acquisition and accumulation $\rightarrow$ business segmentation and value monetization $\rightarrow$ product and process optimization $\rightarrow$ platform function expansion.

First, the business traffic attraction segment is primarily used as the basic function of the platform for traffic acquisition and accumulation. This involves attracting customers from upstream and downstream of the industry chain to set up operations on the platform through information release and providing information consultation interaction, and the gradual establishment of customer stickiness and platform scale and acquisition of customer data through data subsidies, to accurately generate customer profiles and form the business foundation of the platform model.

Second, the platform core segment primarily segregates the business areas to realize value monetization. This involves matching of transaction information and supply and demand for transaction matching, group purchase collection, etc., using of customer information and related data obtained by the business traffic attraction segment, accurate demand positioning for technology empowerment and application markets, gradual formation of different product and service transaction scale, traffic monetization, and deepening of platform attributes and functions.

Third, the security support segment primarily optimizes the form and process of platform core products and services. On the basis of developing the core business of the platform and through further analysis of customer needs, this segment provides credit endorsement, energy insurance, qualification certification, and other related supporting services in terms of brand risk, credit risk, and capital risk, to support the functions of the core segments of the platform.

Fourth, the expansion segment primarily focuses on the future development needs of platform value extension and function expansion. It provides support for platform traffic accumulation, customer retention, and product service process optimization based on the 
overall business logic, through big data services, and basic public energy cloud platform services.

\subsubsection{Platform Business Model Logic under Data Flow}

From the perspective of data flow, the business logic of the smart energy integrated service platform business model is: data acquisition and access $\rightarrow$ data valueadded monetization $\rightarrow$ data precipitation and optimization $\rightarrow$ data management and risk control $\rightarrow$ data value expansion.

First, obtain massive amounts of data from business traffic attraction. Obtain user data and energy data through data subsidies and information release, extract key information through big data analysis and calculation, and complete user-side data perception and accurate user behavior profiles.

Second, connect the business traffic attraction segment and the core platform to complete data distribution and monetization. Provide business service for the platform's core business and assurance support business services, complete data traffic distribution and data value-added monetization through the acquisition and access of big data, and realize accurate information push based on user needs and customized services for different users.

Third, use the platform core to achieve data precipitation and optimization. The core business covering the product services such as application market, technology empowerment, transaction matching, group purchase, and centralized procurement, can be fed back into the acquisition and analysis of user data after a period of data accumulation and precipitation, so as to achieve continuous optimization and upgrade of data flow.

Fourth, realize data management and risk control via the security support segment. This can provide fullprocess risk prevention and control and assurance for the circulation and upgrade of the entire data flow, ensuring that the risks of data acquisition, distribution, and value-added monetization are controllable.

Fifth, use the related functions of the expansion segment for data value mining and expansion. Through big data services and basic public energy cloud platform basic services, further explore the value of data and expand platform functions.

\subsubsection{Platform Business Model Logic under Capital Flow}

From the perspective of capital flow, the business logic of the smart energy integrated service platform business model is: capital investment and subsidy issuance $\rightarrow$ fund acquisition and precipitation $\rightarrow$ reverse fund flow $\rightarrow$ fund risk protection $\rightarrow$ funding channel expansion.

First, the business traffic attraction segment requires early capital investment, which can gradually generate profit in the later stage. It replies on reverse fund flow from other business profits. In the early stages of development, inflow of funds is necessary. Initially, user accumulation and data acquisition can be completed through the free distribution of information and energy data monitoring points. But in the case of a long-term business, membership fees and data acquisition can be collected through customized information consulting services, and charging big data analysis services by acquiring data;

Second, generate profits from other segments based on the business advantages established through business traffic attraction. The business of the platform core and the security support segments primarily fulfill the acquisition, accumulation, and precipitation of funds, generate platform transaction commission, advertising fee, membership fee, bidding service fee, etc. from users through core business, and acquire assurance funds and service commission from users through the supporting business, to provide financial assurance for platform business traffic attraction, development, and operation and maintenance. It feedbacks to business traffic attraction and business expansion segment, ensures continuous optimization and upgrade to generate longterm benefits, and build a capital ecosystem for energy services.

Third, leverage the security support segment to acquire more funding sources and prevent capital risks. In addition to obtaining platform-based income, the segment also controls the risks of the entire capital chain to realize the scientific flow of capital.

Fourth, innovate the platform's income channels by expanding and extending business to create more value. Business expansion primarily focuses on extending future economic benefits and on tapping potential commercial value of the platform through basic services of public energy platform and big data services, in order to create greater economic benefits for the platform.

\subsection{Value Flow Path and Business Process Logic of the Platform Business Model}

Drawing on the logic of the internet platform model and combining the functions and positioning of the smart energy integrated service platform, a typical business closed-loop flow chart is constructed with "traffic attraction $\rightarrow$ traffic distribution $\rightarrow$ traffic monetization" as the value flow path (Figure 2). Irrespective of business flow, data flow, and capital flow, they all follow this value flow path, link up four major business segments, and together constitute the 
business logic of the smart energy integrated service platform.

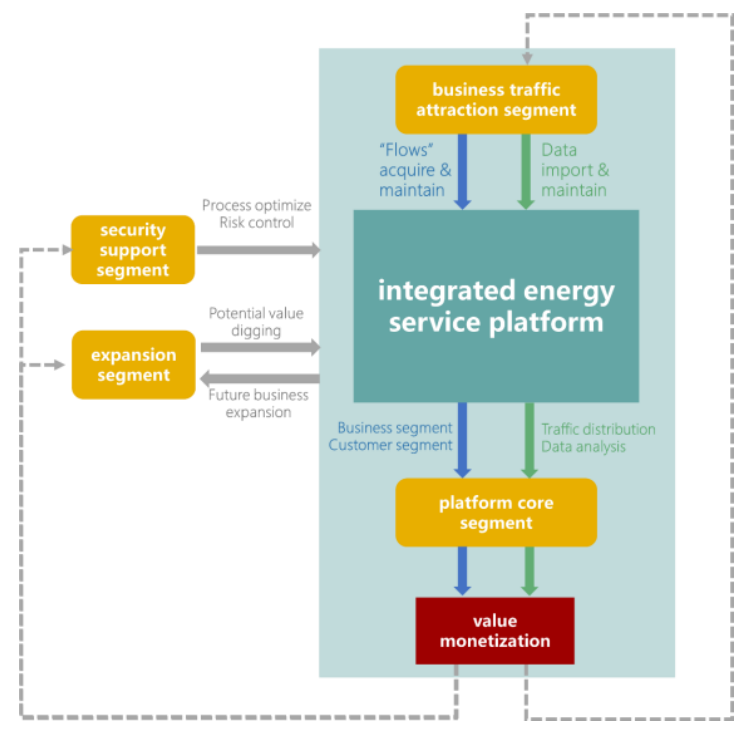

Figure 2 Closed-loop business process of the platform business model.

Traffic attraction provides the platform with traffic acquisition and accumulation, data access, and traffic retention through related products and services; traffic distribution uses the platform to analyze traffic and data to form clear business segmentation and precise customer positioning, and to build core platform products and services; traffic monetization realizes value monetization and data appreciation through the operation and development of various products and services, and provides financial support and business process feedback for the traffic attraction segment.

On this basis, the security support and expansion segments provide process optimization and risk prevention and control, potential value mining, and business development functions for the "traffic attraction $\rightarrow$ traffic distribution $\rightarrow$ traffic monetization" business processes, thereby forming a powerful support for the platform business model.

Of course, these business segments play different types of roles in different business stages. This also requires specific analysis in combination with business practices and development cycles to maximize the function and value of traffic.

\section{CONCLUSION}

Based on the value flow theory, a research framework of the value flow mechanism of the platform business model is constructed and the logic of the platform business model under business flow, data flow, and capital flow is analyzed, in this paper. "Traffic attraction $\rightarrow$ traffic distribution $\rightarrow$ traffic monetization", all promote the development of the platform business model, thereby forming the value flow path of the smart energy integrated service platform business model, and promote the closed loop iteration of business processes. Irrespective of business flow, data flow, and capital flow, the business traffic attraction segment provides the basis for the flow introduction and retention for the overall business process and business model. The platform core segment plays the role of traffic distribution and monetization, while the security support segment, and the expansion segment provide support for process optimization, risk prevention and control, and business expansion.

Value flow theory reveals the basic logic and business process of the smart energy integrated service platform business model, brings a new perspective to the research and practice of the smart energy integrated service platform, and provides a focal point for business cultivation and innovation iterations in the future.

\section{ACKNOWLEDGMENTS}

This research was supported by SGCC Technology Project (SGTYHT/19-JS-215) - Research on energy internet business model design and iteration technology.

\section{REFERENCES}

[1] Schumppeter J., (2009). The theory of economic development: an inquiry into profits, capital, credit, interest, and the business cycle. Beijing: China social sciences press.

[2] Li Z. \& Zhao W. Research on the synergy of enterprise technological innovation with business model innovation. China Soft Science .10(2012):117-124.

[3] Johnson M. W., (2008). Christensen C. M., Kagermann H. Reinventing your business model. Harvard Business Review, 86(12):57-68.

[4] Eisenmann T. (2007). Managing networked businesses: course overview for educators. Harvard Business School.

[5] Stabell, C. B., \& Fjeldstad, Ø. D. (1998). Configuring value for competitive advantage: on chains, shops, and networks. Strategic management journal, 19(5), 413-437.

[6] Liu D., Zhao F., Wang C., (2007). The Study on Innovation of Internet Service Platform of Insurance Intermediary Based on Value Network Theory: A Case Study of CN insure Inc's Chetongnet. Insurance Studies. (09):32-42.

[7] Zhang H., Li T., Xu H., etc. (2019). Research on gert network model of value flow in business network information ecological chain. Information Studies: Theory \& Application, 42(09):35-40+51. 